\title{
Using High Resolution and Dynamic Reaction Cell for the Improvement of the Sensitivity of Direct Silicon Determination in Uranium Materials by Inductively Coupled Plasma Mass Spectrometry
}

\author{
V. M. Golik ${ }^{a}$, N. V. Kuz'mina ${ }^{a}$, A. V. Saprygin ${ }^{a, b}$, and S. A. Trepachev ${ }^{b}$ \\ ${ }^{a}$ JSC Urals Electrochemical Combine, ul. Dzerzhinskogo 2, Novouralsk, Sverdlovsk oblast, 624130 Russia \\ e-mail: czl@ueip.ru \\ ${ }^{b}$ Ural Federal University, ul. Mira 19, Yekaterinburg, 620002 Russia \\ Received December 30, 2011; in final form, February 10, 2012
}

\begin{abstract}
The paper describes solving the problem of direct silicon determination at low levels in uranium materials, caused by the spectral interferences of polyatomic ions and the high value of blank levels, using inductively coupled plasma mass spectrometry (ICP MS). To overcome the interference problem, two primary techniques have been applied: double focusing high-resolution ICP MS and dynamic reaction cell (DRC) filled with highly reactive ammonia gas. All measurements were performed at high resolution $(m / \Delta m=4000)$ on an Element-2 mass spectrometer and pressurized mode of a dynamic reaction cell on an Elan DRC II mass spectrometer. The ways to reducing background levels are investigated. The effects of operating conditions, such as plasma parameters, DRC system original parameters, and uranium matrix influence on the analytical signals of silicon at $m / z=28$ have been observed for different mass spectrometer types. The detection limits and the random error characteristics (relative standard deviation) of silicon determination in uranium materials were estimated.
\end{abstract}

Keywords: inductively coupled plasma mass spectrometry, uranium hexafluoride, silicon, high-resolution mass spectrometer, dynamic reaction cell, weight fraction

DOI: $10.1134 / \mathrm{S} 1061934813130066$

\section{INTRODUCTION}

Silicon is an element forming volatile fluorides; its concentration is restricted both in natural and ${ }^{235} \mathrm{U}-$ enriched uranium hexafluoride. The contemporary system of uranium product quality control assumes the use of reference samples imitating sample composition. Their production requires a matrix, high-purity triuranium octaoxide $\left(\mathrm{U}_{3} \mathrm{O}_{8}\right)$ and uranium hexafluoride $\mathrm{UF}_{6}$ containing certified admixtures. The certification of the matrix requires the procedures which enable determining silicon at the level of $5 \times 10^{-4} \%$ (uranium being taken for $100 \%$ ) and below. The system used for analytical control of admixtures in the products in Central Plant Laboratory of JSC Urals Electrochemical Combine widely uses inductively coupled plasma mass spectrometry (ICP MS). Consequently, the development of the procedures for the silicon determination by this method is an urgent problem.

It should be noted that the direct determination of low silicon concentrations by ${ }^{28} \mathrm{Si}$ isotope by ICP MS is complicated by spectral interference caused by
${ }^{14} \mathrm{~N}^{14} \mathrm{~N}^{+},{ }^{12} \mathrm{C}^{16} \mathrm{O}^{+},{ }^{12} \mathrm{C}_{2} \mathrm{H}_{4}^{+}$ions [1] and the high level of the background signal caused by the memory effect of the mass spectrometer sample introduction system and the concentration of silicon in the air of the working zone (dust particles).

A number of methods are known for reducing spectral interferences with the results of the ICP MS determination of low silicon concentrations in various samples. They include the selection of the optimal parameters of mass spectrometer operation [2], modification of the composition of the plasma-forming gas [3], use of alternative sample injection methods $[4,5]$, direct separation by the isotope weights of the element and interfering ions using high resolution mass spectrometers [6-8], elimination of polyatomic ions using devices for ion-molecule reactions, dynamic reaction cells $[9,10]$.

The analysis of the literature data has demonstrated that the application of high-resolution mass spectrometry is one of the most efficient and simple solutions of the problem of the influence of the main polyatomic interferences in direct ICP MS determination of silicon. The authors of [6-8] have demonstrated that the 
application of $m / \Delta m=4000$ (rel. units) resolution for direct determination of silicon in reagents and biological samples enables the resolution of the peaks of analytes and polyatomic ions with a $\sim 0.02 \mathrm{Da}$ difference in weight numbers. The background level associated with molecular ions is reduced by 5 orders of magnitude compared to the instruments with quadruple mass analyzers. Unfortunately, we did not succeed to find any publications devoted to the analysis of uranium materials.

According to the literature data $[9,10]$, the problem of peak interference can be solved by using mass spectrometers equipped with dynamic reaction cell due to the efficiency and selectivity of the ion-molecule chemical reactions in the cell. Polyatomic ions which get into the cell in the ion beam with the analyte ions interact with the molecules of molecular reaction gas and are eliminated from the ion flow. Thereby, the so-called chemical resolution of the peaks of polyatomic ions and analyte is achieved. The reaction selectivity is achieved through the choice of the reaction gas and electrical parameters of the cell quadruple. However, this method is poorly studied in case of uranium materials and further studies are required for the comprehension of its possibilities and drawbacks.

The aim of the present study was the establishment of the optimal conditions for direct determination of silicon concentration in uranium materials by ICP MS using an Element-2 high-resolution ICP mass spectrometer and an Elan DRC II ICP mass spectrometer equipped with a dynamic reaction cell and the development of sensitive procedures.

\section{EXPERIMENTAL}

Instruments and their parameters. Experiments were performed using two types of ICP mass spectrometers: an Element-2 double focusing sector-field high-resolution mass spectrometer produced by Thermo Electron (output power of the radiofrequency generator is $1200 \mathrm{~W}$, the consumption of the plasmaforming argon flow is $0.96 \mathrm{~L} / \mathrm{min}$, resolution is 4000 , number of measurement per peak is 20, peak width is $400 \%$, electrostatic scanning mode) and an Elan DRC II quadruple mass spectrometer produced by Perkin Elmer Sciex (output power of the radiofrequency generator is $1400 \mathrm{~W}$, consumption of plasmaforming argon flow is $0.85 \mathrm{~L} / \mathrm{min}$, the number of measurement per peak is 20 , peak jumping scanning mode is used, integration time is $2000 \mathrm{~ms}$ ). Elan DRC II mass-spectrometer has two modes of operation: standard one (without reaction gas supply into the cell) and the operation with reaction gas-filled cell.

Double-pass Scott spray chamber and crossflow nebulizer made of mechanically strong polyphenylene sulfide with a carbon filler produced by Ryton were used for sample injection into an Elan DRC II mass spectrometer. Double-pass Scott spray chamber and pneumatic microflow nebulizer of direct injection (self-nebulizing) made of a PFA fluoroplastic were used for the Element-2 mass spectrometer.

Standard samples, solutions and certified mixtures. The following solutions were used for the experiments:

(i) MSO 0130:2000 standard silicon ion solution containing $(1.00 \pm 0.05) \mathrm{mg} / \mathrm{mL}$ silicon;

(ii) uranyl fluoride solution obtained by hydrolysis of uranium hexafluoride depleted by ${ }^{235} \mathrm{U}$ isotope with deionized water. Weight concentration of uranium in the solution was $0.2 \mathrm{~g} \mathrm{U}$ per gram of solution;

(iii) certified mixtures: solutions with weight concentration of silicon of $100 \mu \mathrm{g} / \mathrm{L}$ and $1 \mathrm{mg} / \mathrm{L}$ and uranium weight concentration of $1 \mathrm{~g} / \mathrm{L}$ prepared using the solutions listed above.

Reduction of the blank experiment correction. Silicon abundance in nature and its ubiquitous presence requires correct account of the memory effects of the instruments and signals of the blank experiment for the development of the procedures of its determination. In order to avoid the contamination of the test solutions with silicon and reduce the blank experiment correction, we studied the influence of the purification quality of water used for sample dilution on the background signal intensity. In addition, before the experiment the sample injection system was washed with 5\% nitric acid for two hours for the reduction of the instrument memory effect, the cones were additionally purified in deionized water in an ultrasound bath, the spray chambers were preliminary soaked in a 5\% solution of hydrofluoric acid, demounable pars of the torch were cleansed in high-purity water. The procedure of sample treatment and injection excluded the use of glasswear and glass details in the system of sample injection. The solutions were prepared in polypropylene volumetric flasks produced by VitLab.

In order to reduce the silicon concentration in the solution of uranyl fluoride which was used as the uranium-containing matrix for the preparation of the certified mixtures, it was proposed to perform additional purification of this solution by distillation of the volatile compounds of silicon $\left(\mathrm{SiF}_{4}\right)$. A weighed portion of uranyl fluoride obtained by hydrolysis of uranium hexafluoride containing at least $2.5 \mathrm{~g}$ of uranium was placed into a platinum tray and its contents were evaporated to direness at $160^{\circ} \mathrm{C}$ using an IR heater. The dry residue after the evaporation was dissolved in deionized water and used for the preparation of certified mixtures.

Theoretical study of the possibility of elimination of spectral interferences using high resolution and dynamic reaction cell. The silicon isotope with weight number of 28 Da was chosen among all natural silicon isotopes for the mass spectrometry measurements. This isotope has the highest natural abundance (92.83\% [11]).

Table 1 shows the main interferences of polyatomic ions for ${ }^{28} \mathrm{Si}$ isotope and the values of the mass spectrometer resolving ability $(R)$ required for their elimi- 
Table 1. The main spectral interferences of polyatomic ions for ${ }^{28} \mathrm{Si}$ silicon isotope [1]

\begin{tabular}{c|c|c|c|c}
\hline $\begin{array}{c}\text { Isotope and its natural } \\
\text { abundance (in the } \\
\text { brackets), [11] }\end{array}$ & $\begin{array}{c}\text { Isotope atomic weight, } \\
\text { Da [11] }\end{array}$ & $\begin{array}{c}\text { Spectral } \\
\text { interference } \\
{[1]}\end{array}$ & $\begin{array}{c}\text { Molecular weight } \\
\text { of polyatomic ion, } \\
\text { Da [11] }\end{array}$ & $\begin{array}{c}\text { Resolution required } \\
\text { for the separation from } \\
\text { silicon isotope, } \\
\text { rel. units }\end{array}$ \\
\hline${ }^{28} \mathrm{Si}(92.23 \%)$ & 27.9769 & ${ }^{14} \mathrm{~N}_{2}^{+}$ & 28.0061 & 958 \\
& ${ }^{12} \mathrm{C}^{16} \mathrm{O}^{+}$ & 27.9949 & 1557 \\
& ${ }^{12} \mathrm{C}_{2}{ }^{1} \mathrm{H}_{4}^{+}$ & 28.0313 & 504 \\
& & ${ }^{12} \mathrm{C}_{2} \mathrm{H}_{2}{ }^{14} \mathrm{~N}^{+}$ & 28.0187 & 670 \\
\hline
\end{tabular}

nation. These values were calculated using the equation

$$
R=m_{\mathrm{Si}} /\left(m_{\mathrm{Si}}-m_{\mathrm{IC}}\right)
$$

where $m_{\mathrm{Si}}$ is the relative atomic weight of silicon isotope, $\mathrm{Da} ; m_{\mathrm{IC}}$ is the relative molecular weight of the interfering cation, Da.

Table 1 shows that the problem of interference of the peaks of silicon and polyatomic ions can be easily solved by the increase in the equipment resolving ability $R$ to 2000 due to the difference in weights $(\sim 0.02 \mathrm{Da})$ of silicon isotopes and isotopes of the interfering ions. The resolution of $R=4000$ was used for the measurement of the silicon concentration in uranium hexafluoride using an Element-2 mass spectrometer.

According to literature data $[5,9,10]$, ammonia is the most appropriate reaction gas for ICP MS determination of silicon concentration by ${ }^{28} \mathrm{Si}$ isotope. According to the recommendations for gas selection provided in [12] and taking into account the thermodynamic properties of gases provided in Table 2, direct determination of silicon by ICP MS using dynamic reaction cell can be also performed with oxygen, methane, and hydrogen. For the section of the suitable reaction gas we carried out preliminary detailed esti-

Table 2. Thermochemical properties of the reaction gases

\begin{tabular}{l|c|c}
\hline Reaction gas & $\begin{array}{c}\text { Molecular weight, } \\
\text { g [11] }\end{array}$ & $\begin{array}{c}\text { onization energy, } \\
\text { eV [11] }\end{array}$ \\
\hline $\mathrm{CH}_{4}$ & 16.04 & 12.61 \\
$\mathrm{CO}$ & 28.01 & 14.01 \\
$\mathrm{CO}_{2}$ & 44.01 & 13.79 \\
$\mathrm{C}_{2} \mathrm{H}_{6}$ & 30.07 & 11.52 \\
$\mathrm{H}_{2}$ & 2.02 & 15.43 \\
$\mathrm{NH}_{3}$ & 17.03 & 10.07 \\
$\mathrm{NO}$ & 30.01 & 9.26 \\
$\mathrm{~N}_{2} \mathrm{O}$ & 44.01 & 12.89 \\
$\mathrm{O}_{2}$ & 32.0 & 12.07 \\
$\mathrm{Xe}$ & 131.0 & 12.13 \\
\hline
\end{tabular}

mation of the kinetic and thermodynamic parameters of ion-molecule reaction which proceed using these gases. Table 3 provides the equations of the possible ion-molecule reactions of polyatomic ions with the selected reaction gases, reaction enthalpy values and the constants of reaction kinetic rate. The value of enthalpy for each ion-molecule reaction $\Delta H_{\mathrm{r}}$ was calculated by equation (2) using the reference data provided in [15]. The reaction rate constants $k_{\mathrm{r}}$ were taken from [16].

$$
\Delta H_{\mathrm{r}}=\Sigma \Delta H_{\mathrm{f}}(\text { Products })-\Sigma \Delta H_{\mathrm{f}}(\text { Reagents }) .
$$

Here $\Delta H_{\mathrm{f}}$ is enthalpy (of heat) of compound formation, i.e., the heat required for the transition (transformation) of the elements which compose this compounds from their standard state into the compounds at constant pressure.

The analysis of thermodynamic and kinetic parameters of ion-molecule reactions of polyatomic ions with reaction gases given in Table 3 demonstrated that all the chosen gases could be used for the determination of silicon concentration by ${ }^{28} \mathrm{Si}$ isotope since the reactions of polyatomic ions with the reaction gases were exothermic $\left(\Delta H_{\mathrm{r}}<0\right)$ and, consequently, thermodynamically favorable. However, ammonia should be considered to be the most suitable gas for the detection of silicon since the reactions of polyatomic ions with $\mathrm{NH}_{3}$ are more efficient and proceed with higher rate as compared to other gases $\left(k_{\mathrm{r}}=2 \times 10^{-9} \mathrm{~cm}^{3} \mathrm{~mol}-\right.$ ecule $\left.^{-1} \mathrm{~s}^{-1}\right)$.

\section{RESULTS AND DISCUSSION}

In order to confirm the possibility of eliminating the polyatomic interference onto ${ }^{28} \mathrm{Si}$ isotope by high resolution mode, we scanned a part of mass spectrum at low $(R=300)$ and high $(R=4000)$ resolution in the analysis of a solution containing $100 \mu \mathrm{g} / \mathrm{L}$ silicon. Figure 1 shows the mass spectra obtained for ${ }^{28} \mathrm{Si}$ isotope with low and high resolution, respectively.

As Fig. 1a shows, at low resolution the analytical signals of the ${ }^{28} \mathrm{Si}$ isotope and ${ }^{14} \mathrm{~N}-{ }^{14} \mathrm{~N},{ }^{16} \mathrm{O}-{ }^{12} \mathrm{C}$ form one common unresolved peak. Under such conditions it is difficult to determine silicon. At the same time, at 
Table 3. Thermodynamic and kinetic parameters of ion-molecule reactions of the main polyatomic ions $(\mathrm{m} / z=28 \mathrm{Da})$ with the reaction gases

\begin{tabular}{|c|c|c|c|}
\hline Polyatomic ion & Ion-molecular reaction equation & $\begin{array}{c}\text { Reaction enthalpy, } \Delta H_{\mathrm{r}}, \\
\mathrm{kcal} / \mathrm{mol}\end{array}$ & $\begin{array}{l}\text { Reaction rate constant, } \\
k_{\mathrm{r}}, \mathrm{cm}^{3} \text { molecule } \mathrm{c}^{-1} \mathrm{~s}^{-1}[16]\end{array}$ \\
\hline \multirow{9}{*}{$\mathrm{N}_{2}^{+}$} & $\mathrm{N}_{2}^{+}+\mathrm{O}_{2} \longrightarrow \mathrm{N}_{2}+\mathrm{O}_{2}^{+}$ & -81.40 & $1.00 \times 10^{-10}$ \\
\hline & $\longrightarrow \mathrm{NO}^{+}+\mathrm{NO}$ & -102.54 & $2.1 \times 10^{-13}$ \\
\hline & $\mathrm{N}_{2}^{+}+\mathrm{H}_{2} \longrightarrow \mathrm{N}_{2}+\mathrm{H}_{2}^{+}$ & -3.46 & No data \\
\hline & $\longrightarrow \mathrm{N}_{2} \mathrm{H}^{+}+\mathrm{H}$ & No data & $1.47 \times 10^{-10}$ \\
\hline & $\mathrm{N}_{2}^{+}+\mathrm{CH}_{4} \longrightarrow \mathrm{N}_{2}+\mathrm{CH}_{4}^{+}$ & -71.26 & $1.1 \times 10^{-9}$ \\
\hline & $\longrightarrow \mathrm{CH}_{3}^{+}+\mathrm{N}_{2}+\mathrm{H}$ & -29.05 & $9.80 \times 10^{-10}$ \\
\hline & $\longrightarrow \mathrm{CH}_{2}^{+}+\mathrm{N}_{2}+\mathrm{H}_{2}^{+}$ & -12.18 & No data \\
\hline & $\mathrm{N}_{2}^{+}+\mathrm{NH}_{3} \longrightarrow \mathrm{N}_{2}+\mathrm{NH}_{3}^{+}$ & -124.99 & $2.02 \times 10^{-9}$ \\
\hline & $\longrightarrow \mathrm{N}_{2} \mathrm{H}^{+}+\mathrm{NH}_{2}$ & No data & $1.80 \times 10^{-9}$ \\
\hline \multirow{8}{*}{$\mathrm{CO}^{+}$} & $\mathrm{CO}^{+}+\mathrm{O}_{2} \longrightarrow \mathrm{CO}+\mathrm{O}_{2}^{+}$ & -44.74 & $1.5 \times 10^{-10}$ \\
\hline & $\longrightarrow \mathrm{CO}_{2}^{+}+\mathrm{O}$ & -13.19 & $1.0 \times 10^{-10}$ \\
\hline & $\mathrm{CO}^{+}+\mathrm{H}_{2} \longrightarrow \mathrm{CO}+\mathrm{H}_{2}^{+}$ & 32.75 & No data \\
\hline & $\longrightarrow \mathrm{HCO}^{+}+\mathrm{H}$ & -45.55 & $1.19 \times 10^{-9}$ \\
\hline & $\mathrm{CO}^{+}+\mathrm{CH}_{4} \longrightarrow \mathrm{CO}+\mathrm{CH}_{4}^{+}$ & -34.59 & $1.34 \times 10^{-9}$ \\
\hline & $\longrightarrow \mathrm{HCO}^{+}+\mathrm{CH}_{3}$ & -44.94 & $1.37 \times 10^{-9}$ \\
\hline & $\mathrm{CO}^{+}+\mathrm{NH}_{3} \longrightarrow \mathrm{CO}+\mathrm{NH}_{3}^{+}$ & -78.4 & $2.04 \times 10^{-9}$ \\
\hline & $\longrightarrow \mathrm{HCO}^{+}+\mathrm{NH}_{2}$ & -41.18 & No data \\
\hline \multirow{5}{*}{$\mathrm{C}_{2} \mathrm{H}_{4}^{+}$} & $\mathrm{C}_{2} \mathrm{H}_{4}^{+}+\mathrm{O}_{2} \longrightarrow \mathrm{C}_{2} \mathrm{H}_{4}+\mathrm{O}_{2}^{+}$ & 37.5 & $5 \times 10^{-13}$ \\
\hline & $\mathrm{C}_{2} \mathrm{H}_{4}^{+}+\mathrm{H}_{2} \longrightarrow \mathrm{C}_{2} \mathrm{H}_{4}+\mathrm{H}_{2}^{+}$ & 114.9 & $4 \times 10^{-14}$ \\
\hline & $\mathrm{C}_{2} \mathrm{H}_{4}^{+}+\mathrm{CH}_{4} \longrightarrow \mathrm{C}_{2} \mathrm{H}_{4}+\mathrm{CH}_{4}^{+}$ & 30.5 & $3 \times 10^{-12}$ \\
\hline & $\mathrm{C}_{2} \mathrm{H}_{4}^{+}+\mathrm{NH}_{3} \longrightarrow \mathrm{NH}_{3}^{+}+\mathrm{C}_{2} \mathrm{H}_{4}$ & -7.84 & $1.80 \times 10^{-9}$ \\
\hline & $\longrightarrow \mathrm{NH}_{4}^{+}+\mathrm{CHCH}_{2}$ & -26.94 & $2.06 \times 10^{-9}$ \\
\hline \multirow{4}{*}{$\mathrm{C}_{2} \mathrm{H}_{2} \mathrm{~N}^{+}$} & $\mathrm{C}_{2} \mathrm{H}_{2} \mathrm{~N}^{+}+\mathrm{O}_{2} \longrightarrow \mathrm{C}_{2} \mathrm{H}_{2} \mathrm{~N}+\mathrm{O}_{2}^{+}$ & 28.5 & No data \\
\hline & $\mathrm{C}_{2} \mathrm{H}_{2} \mathrm{~N}^{+}+\mathrm{H}_{2} \longrightarrow \mathrm{C}_{2} \mathrm{H}_{2} \mathrm{~N}+\mathrm{H}_{2}^{+}$ & 105.9 & No data \\
\hline & $\mathrm{C}_{2} \mathrm{H}_{2} \mathrm{~N}^{+}+\mathrm{CH}_{4} \longrightarrow \mathrm{C}_{2} \mathrm{H}_{2} \mathrm{~N}+\mathrm{CH}_{4}^{+}$ & 21.6 & No data \\
\hline & $\mathrm{C}_{2} \mathrm{H}_{2} \mathrm{~N}^{+}+\mathrm{NH}_{3} \longrightarrow \mathrm{NH}_{3}^{+}+\mathrm{C}_{2} \mathrm{H}_{2} \mathrm{~N}$ & -17.06 & No data \\
\hline
\end{tabular}

$\Delta H_{\mathrm{r}}$ value was calculated using equation (2).

high resolution (Fig. 1b) the peaks corresponding to ${ }^{28} \mathrm{Si}$ and ${ }^{14} \mathrm{~N}-{ }^{14} \mathrm{~N},{ }^{16} \mathrm{O}-{ }^{12} \mathrm{C}$ are completely resolved and enable confident determination of silicon.

Estimation of the reactivity of ammonia towards polyatomic ions and ${ }^{28} \mathrm{Si}^{+}$. The selection of the optimal reaction gas consumption. In the experiment for the estimation of the reactivity of ammonia and the selection of the optimal consumption of the reaction gas in a Elan DRC II mass spectrometer operating in the mode of gas supply into the cell we analyzed the solu- tion containing $1 \mathrm{~g} / \mathrm{L}$ of uranium (blank experiment) and the solution with silicon weight concentration of $1 \mathrm{mg} / \mathrm{g}$ uranium (certified mixture). The both solutions were prepared from uranylfluoride solution which was preliminary purified from silicon by distillation. In the experiment the ammonia consumption was varied in the range from 0 to $1 \mathrm{~mL} / \mathrm{min}$ with a $0.1 \mathrm{~mL} / \mathrm{min}$ step. The consumption of the gas in the cell was set by the controlling flow meter which was calibrated by nitrogen. The correction factor for the 
(a)

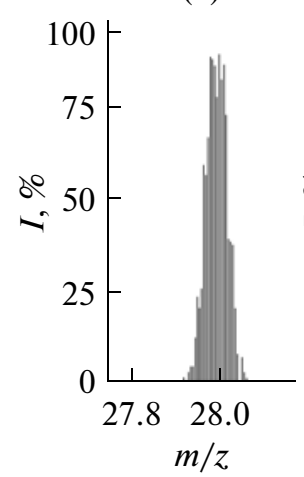

(b)

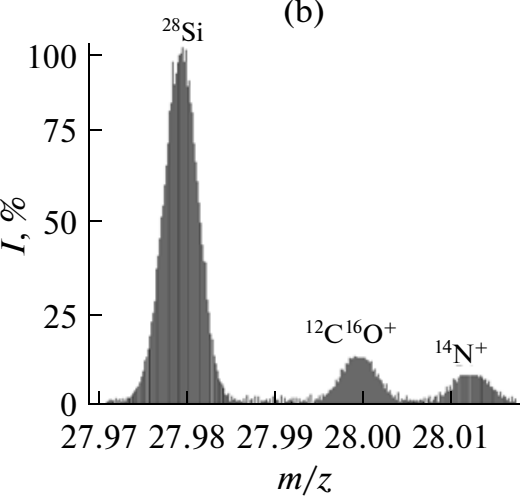

Fig. 1. Relative intensity of the analytical signal $(I)$ at $m / z$ 28: the region of mass spectra obtained in the mode of low $(R=300)(\mathrm{a})$ and high $(R=4000)$ (b) resolution.

calculation of ammonia consumption is given in [12]. Electrical parameters of $\mathrm{RPa}$ and $\mathrm{RP} q$ quadruple (according to the recommendations of authors of [13]) were 0 and $0.55 \mathrm{~V}$, respectively. For each of the two solutions we obtained the dependences of the analytical signal intensities at the weight of $28 \mathrm{Da}$ on $\mathrm{NH}_{3}$ consumption. The signals obtained in the analysis of the blank sample were interpreted as background signals from polyatomic ions. The analytical signals of $\mathrm{Si}$ were calculated by the difference of the signals measured at the weight of $28 \mathrm{Da}$, in the solution of certified mixture and blank sample. The resultant dependences of the analytical and background signals on the consumption of the reaction gas in the cell are provided in Fig. 2a. Obviously, the increase in ammonia consumption results in the reduction of the signal in the solution of the blank sample. The curve slope in the beginning evidences of a rather rapid reaction of $\mathrm{CO}^{+}$, $\mathrm{C}_{2} \mathrm{~N}_{4}^{+}, \mathrm{C}_{2} \mathrm{H}_{2} \mathrm{~N}^{+}$and $\mathrm{N}_{2}^{+}$ions with ammonia.

The observed signal reduction in the solution of the certified mixture with the increase in the gas consumption can be associated with the ion- molecule reactions of silicon with ammonia yielding ion-molecule complexes $\mathrm{Si}\left(\mathrm{NH}_{3}\right)^{+}, \mathrm{Si}\left(\mathrm{H}_{2} \mathrm{O}\right)^{+}$(as a result of association reaction) and $\mathrm{SiNH}_{2}^{+}$(as a result of the reaction of hydrogen atom transfer).

Since according to the experimental data (Fig. 2a) the analytical signal is observed to decrease both in the analysis of blank sample and certified mixture, we chose the value of the single-to-noise ratio as the criterion for the selection of the optimal consumption of the reaction gas. According to the experimental data (Fig. 2b), the best ratio of the analytical signal to the background signal was achieved when the reaction gas consumption was $0.1 \mathrm{~mL} / \mathrm{min}$. Under these conditions the background signal decreases significantly as compared with the silicon analytical signal; it means that chemical resolution of the interfering ions and sil-

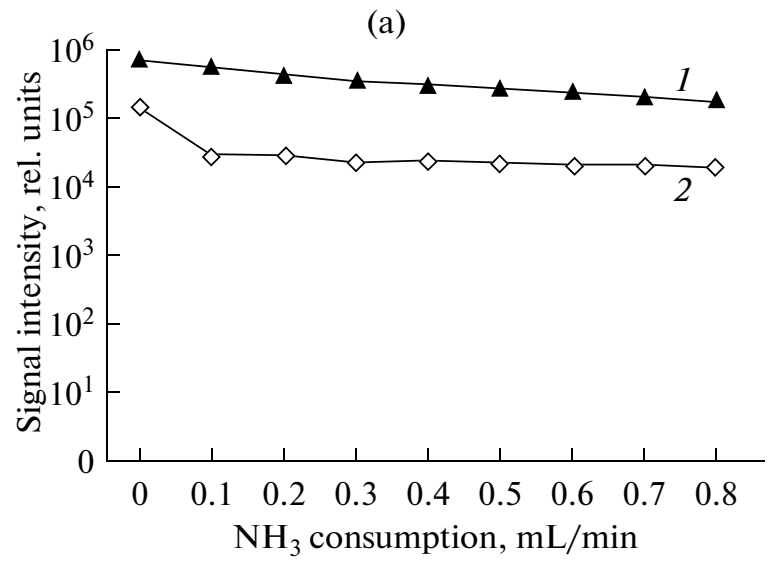

(b)

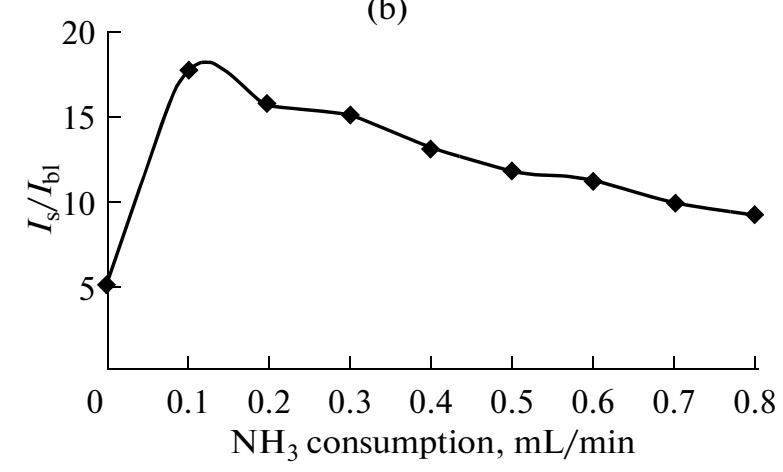

Fig. 2. Influence of the consumption of the reaction gas in the $\mathrm{NH}_{3}$ cell on the silicon analytical signal; (a) is the dependence of the analytical signal of silicon (1) and background signal (2) at $m / z 28$; (b) is the dependence of the signal-to-noise ratio $\left(I_{\mathrm{s}} / I_{\mathrm{b} 1}\right)$.

icon occurs and ammonia has high reactivity towards $\mathrm{N}_{2}^{+}, \mathrm{CO}^{+}, \mathrm{C}_{2} \mathrm{H}_{4}^{+}$, and $\mathrm{C}_{2} \mathrm{H}_{2} \mathrm{~N}^{+}$ions.

Despite the fact that the background level generated by polyatomic interferences can be decreased using one or another method, there is one more important problem, high level of the blank experiment signal, which is mentioned in all the studies devoted to ICP MS determination of low silicon concentration [6-8]. In order to study the influence of water and uranyl fluoride used for the preparation of the reference samples (certified mixtures) on the intensity of the background signal in Element-2 mass spectrometer in the mode of medium resolution, the intensity of silicon signal was subsequently measured in the solutions of the blank sample, solutions of deionized water with the addition of silicon and certified mixture with the weight concentration of silicon of $100 \mu \mathrm{g} / \mathrm{L}$ and uranium concentration $1 \mathrm{~g} / \mathrm{L}$ prepared using deionized water obtained on different purification systems and different hydrolysates of uranium hexafluoride (initial and after purification). The aim of this study was the estimation of the signal-to-noise ratio which determined the detection limit and the selection of the matrix for the preparation of the solution with the 
(a)
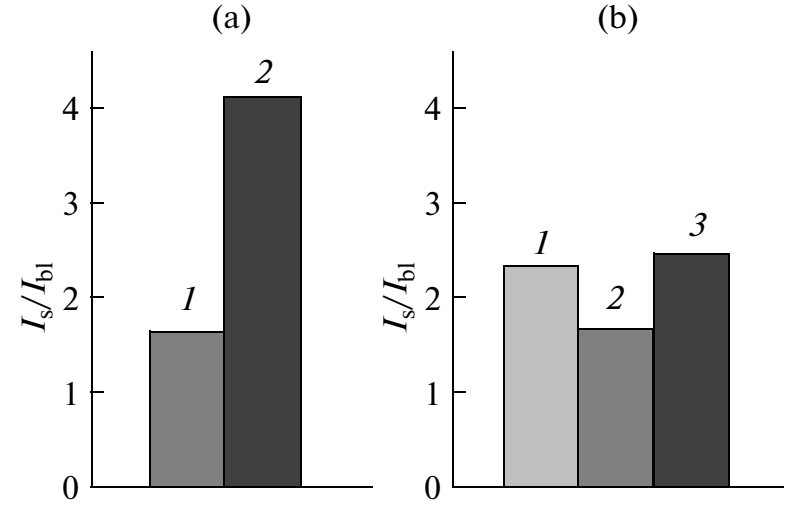

Fig. 3. Dependence of the signal-to-noise ratio $I_{\mathrm{s}} / I_{\mathrm{bl}}$ on the hydrolyzed uranium hexafluoride (a) (initial substance (1), after purification from silicon by distillation (2)) and on deionized water obtained after different purification systems (b) (Milli-Q Element (Millipore) (1), Maxima (Elga) (2), Direct-Q (Millipore) (3)).

maximal value of this parameter. The results are provided in Fig. 3.

According to the experimental results (Fig. 3), for the preparation of the solutions of samples and certified mixture one should use deionized water obtained after Direct-Q purification system and hydrolyzed uranium hexafluoride preliminary purified by distillation since they are the purest components in terms of silicon concentration.

Determination of the optimal conditions for direct determination of silicon in uranium materials by ICP MS. In order to select the optimal parameters of operation of each ICP mass spectrometer, we carried out an experiment where the power of radiofrequency generator was subsequently changed in the range from 900 to $1400 \mathrm{~W}$ with a $100 \mathrm{~W}$ step and the analytical signal of silicon was registered. For each value of the radiofrequency generator power, the nebulizer gas consumption and voltage on the ion optics elements was optimized. Figure 4 shows the dependences of the relative value of the analytical signal on the power of radiofrequency generator presented in normalized coordinates $I / I_{\max }$-generator power, where $I$ is the intensity of the analytical single registered for this power and $I_{\max }$ is the maximal intensity of the analytical signal registered in the experiment.

The results of the experiment demonstrated that the maximal sensitivity toward silicon is achieved at the power of radiofrequency generator of $1200 \mathrm{~W}$ in the high-resolution mode (Element-2), $1400 \mathrm{~W}$ in the mode the reaction cell operation filled with the reaction gas (Elan DRC II), the optimal value of nebulizer gas consumption being 0.96 and $0.83 \mathrm{~L} / \mathrm{min}$, respectively.

Optimization of the operation parameters of dynamic reaction cell. According to literature data [12, 13], the most important parameters influencing the

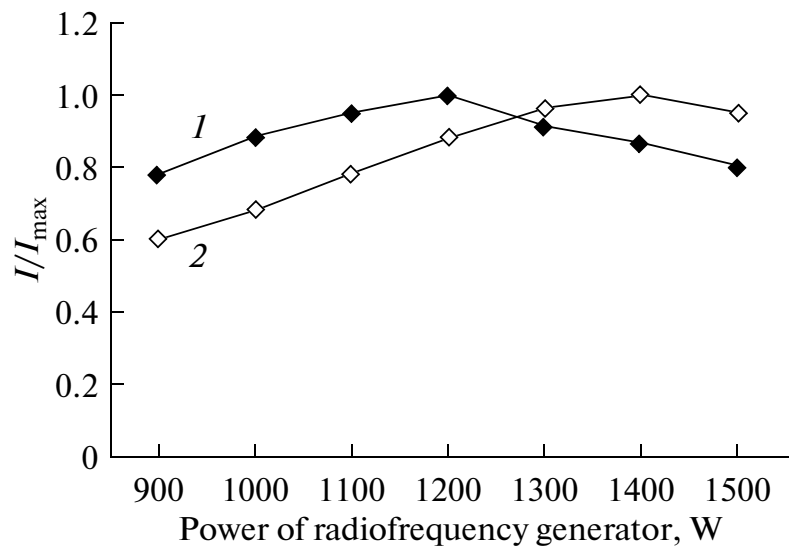

Fig. 4. Dependence of the relative value of the silicon analytical signal on the power of radiofrequency generator: (1) Element-2, (2) Elan DRC II.

efficiency of dynamic reaction cell operation are the consumption of the reaction gas and high-frequency $(\mathrm{RP} q)$ and constant ( $\mathrm{RP} a)$ components of the voltage applied to the cell quadruple. In addition, a number of special parameters should be adjusted: accelerating voltage $U_{\mathrm{CPV}}$, constant voltage applied to the rods of cell quadruple $U_{\mathrm{CRO}}$, constant voltage applied to the rods of mass analyzer quadruple $U_{\mathrm{QRO}}$.

For the optimization of the values of $U_{\mathrm{CPV}}, U_{\mathrm{CRO}}$, $U_{\mathrm{QRO}}$ parameters the analytical signal of silicon was registered in a certified mixture with the weight concentration of silicon of $1 \mathrm{mg}$ per $1 \mathrm{~g}$ of uranium in the cell operation mode with ammonia consumption of $0.1 \mathrm{~mL} / \mathrm{min}$ at different values of each parameter. The criterion of the determination of the optimal values of these parameters was the maximal intensity of the analytical signal. Figure 5 presents the dependences of the relative $\left(I / I_{\max }\right)$ value of silicon analytical signal on the value of the considered parameter. The experimentally chosen optimal values of parameters $U_{\mathrm{CPV}}, U_{\mathrm{CRO}}, U_{\mathrm{QRO}}$ were $-19,-2$ and $-5 \mathrm{~V}$, respectively.

Due to the small difference in the pressures in the cell and vacuum chamber of the mass spectrometer in addition to argon the reaction gas can contain $\mathrm{H}, \mathrm{O}$, $\mathrm{N}$, and $\mathrm{C}$ containing admixtures and water molecules. The ion-molecule reactions between the admixtures and the reaction gas yield $\mathrm{C}_{m} \mathrm{H}_{y}^{-}, \mathrm{C}_{m} \mathrm{H}_{y} \mathrm{O}^{+}, \mathrm{C}_{m} \mathrm{O}^{+}$ions which interfere in a wide range of the mass spectrum and reduce the efficiency of the cell operation. However, the cell quadruple is characterized by certain limits of stability which can be changes. The regions of quadruple stability and instability are described by parameters $a$ and $q$ in Mathieu equation [12] and depend on the amplitude and the frequency of the applied radiofrequency voltage $\left(V_{\mathrm{rf}}\right)$, ion mass, geometric size of the quadruple and constant voltage applied between the pairs of any poles $\left(V_{\mathrm{dc}}\right)$. 

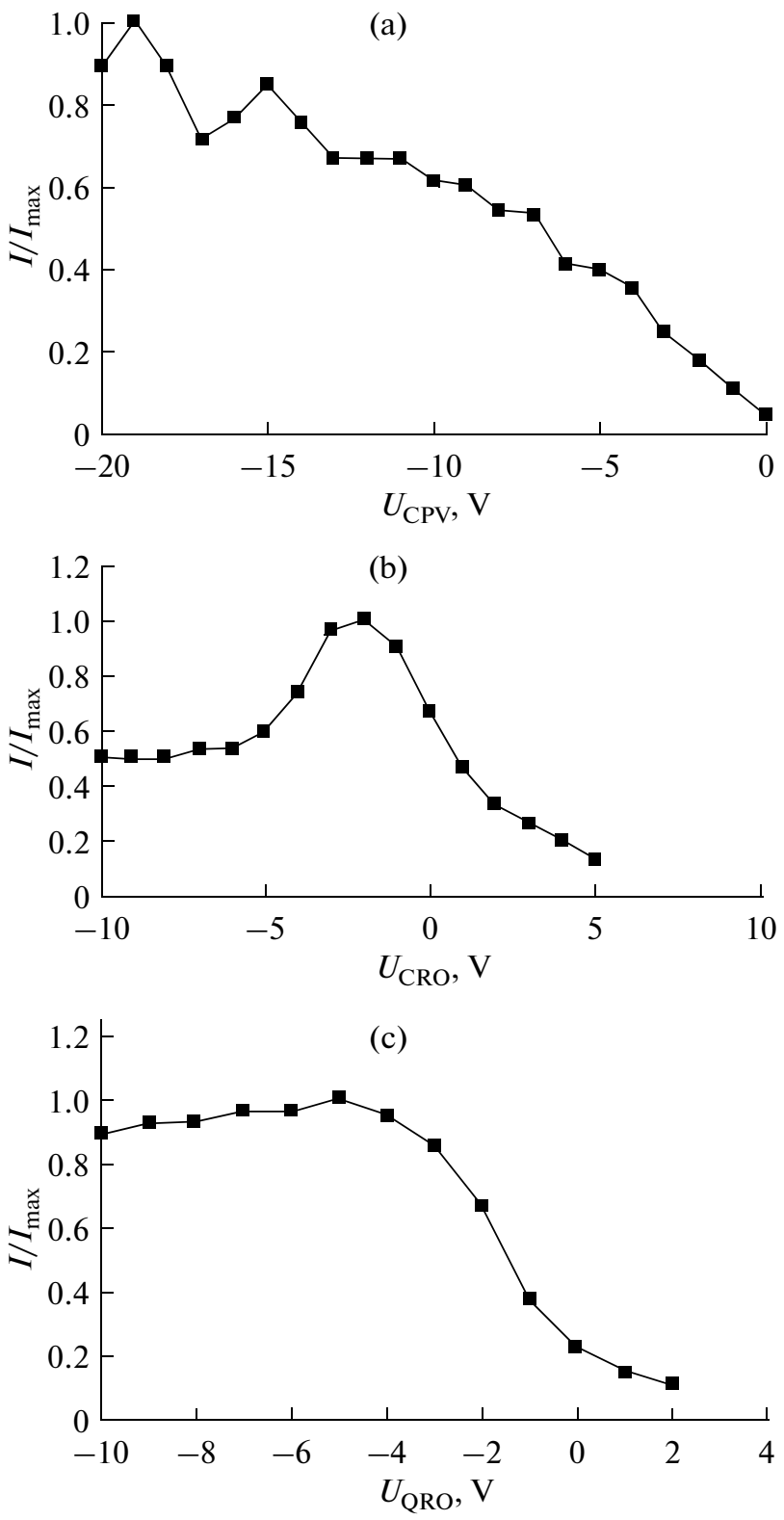

Fig. 5. Dependence of the relative value of the silicon analytical signal on the value of the accelerating voltage $U_{\mathrm{CPV}}$ (a), constant voltage $U_{\mathrm{CRO}}$, applied to the cell quadruple rods (b), constant voltage $U_{\mathrm{QRO}}$ applied to the mass analyzer quadruple rods (c).

The software of Elan DRC II mass spectrometer sets $a$ and $q$ parameters by the values of $\mathrm{RP} a$ and $\mathrm{RP} q$ and they are calculated by the equations:

$$
\begin{gathered}
\mathrm{RP} q=q / 0.95, \\
\mathrm{RP} a=a / 1.9 .
\end{gathered}
$$

If only alternating voltage $\left(V_{\mathrm{dc}}=0, a=0\right)$ is applied onto the rods of the cell quadruple, the lower weight limit $\left(m_{\text {lower }}\right)$ of the transmission interval can be calculated by equation (5) [14]

$$
m_{\text {low }}=(\mathrm{RP} q / 0.956) m_{\mathrm{an}} \text {. }
$$

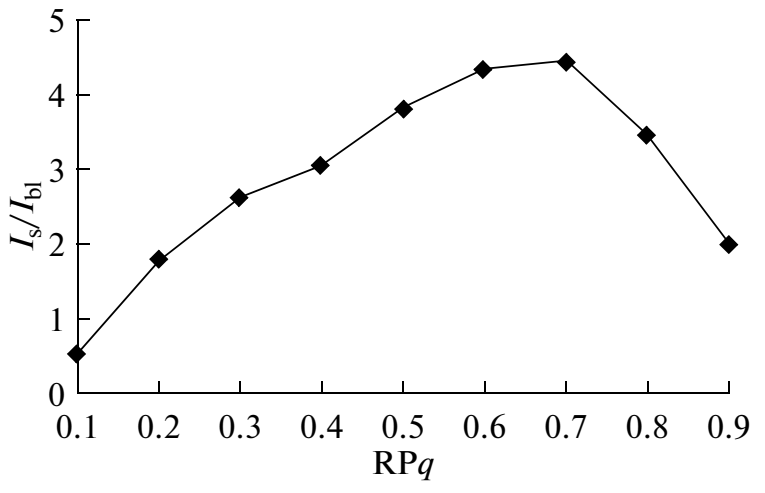

Fig. 6. Dependence of the signal-to-noise ratio $I_{\mathrm{S}} / I_{\mathrm{bl}}$ for $m / z 28$ registration on the value of high-frequency voltage applied to the rods of cell quadruple $(\mathrm{RP} q)$.

The detection limit can be improved for different elements and the boundaries of the transmission interval can become more pronounced if constant voltage is applied to the cell quadruple $\left(V_{\mathrm{dc}}>0, a>0\right)$. According to the data of [14], at RPa $\leq 0.05$, the lower boundary of the transmission interval $\left(m_{\text {low }}\right)$ can be calculated by Eq. (5).

As the calculation shows, the value of RPa parameter hardly influences the lower boundary of the transmission interval at the weight of $m_{\text {an }}=28 \mathrm{Da}$, so the subsequent experiments were measured at $\mathrm{RP} a=0$.

In the experiment on the study of the $\mathrm{RP} q$ value influence on the analytical signal intensity of Elan DRC II mass spectrometer (cell operation mode) we also tested two solutions (the blank sample and certified mixture). For each of them the dependence of the analytical signal intensity at the weight of $28 \mathrm{Da}$ on the value of the radiofrequency voltage applied to the cell quadruple was established. The value of RP $q$ parameter was varied stepwise in the range from 0.1 to $0.9 \mathrm{~V}$; ammonia consumption in the cell was constant $(0.1 \mathrm{~mL} / \mathrm{min})$. In order to make the final choice of the optimal value of $\mathrm{RP} q$ parameter, we constructed the dependence of the single-to-noise ratio. This plot is shown in Fig. 6.

According to the data of Fig. 6, the maximal signalto-noise ratio is observed when $\mathrm{RP} q$ parameter is 0.7 . The reduction of this parameter at $\mathrm{RP} q>0.7$ can be explained by the decrease in the analytical signal intensity due to the reaction between ${ }^{28} \mathrm{Si}^{+}$ion and $\mathrm{NH}_{3}$ leading to the losses of the analyte $[12,13]$ :

$$
\mathrm{Si}^{+}+\mathrm{NH}_{3} \rightarrow \mathrm{Si}+\mathrm{NH}_{3}^{+} .
$$

Low values $\mathrm{RP} q<0.5$ create the advantageous conditions for the side reaction involving the interfering ion with smaller weight (for example, $m / z$ 12) and neutral gas molecules leading to the formation of new interfering ions with the weight number of $28 \mathrm{Da}$ :

$$
\begin{gathered}
{ }^{12} \mathrm{C}^{+}+\mathrm{NH}_{3} \rightarrow \mathrm{NCNH}^{+}+\mathrm{H} \\
k_{\mathrm{r}}=4.6 \times 10^{-9} \mathrm{~cm}^{3} \text { molecule }{ }^{-1} \mathrm{~s}^{-1} .
\end{gathered}
$$




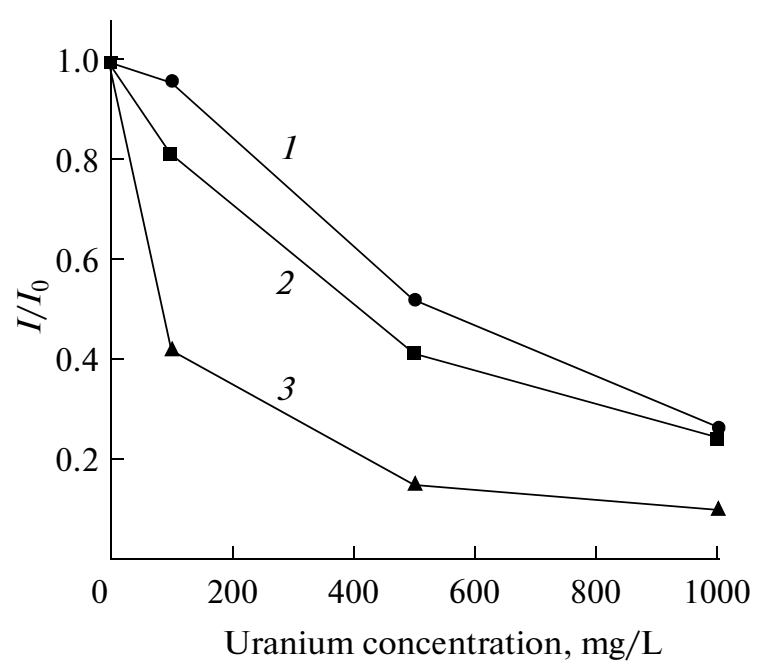

Fig. 7. Dependence of silicon analytical signal $\left(I / I_{0}\right)$ on uranium concentration in the solution obtained using (1) Element-2, (2) Elan DRC II, standard mode, (3) Elan DRC II, cell mode.

Investigation of uranium influence on the silicon analytical signal. In order to study the influence of uranium on silicon determination by ICP MS, we analyzed the solutions with different uranium concentrations and addition of $100 \mu \mathrm{g} / \mathrm{L}$ silicon (certified mixtures) using the high resolution mode of Element-2 mass spectrometer and different operation modes of Elan DRC II mass spectrometer. Figure 6 presents the dependences of the intensity of silicon analytical signal on uranium concentration in certified mixtures. The dependences are given in normalized coordinates $I / I_{0}$-uranium concentration where $I$ is the analytical signal in the presence of uranium, $I_{0}$ is the analyte signal in the absence of uranium.

The results of the experiments have demonstrated (Fig. 7) that regardless of the mass spectrometer type the increase in uranium concentration in the solution leads to significant (80-90\%) suppression of silicon analytical signals. However, it should be noted that when the cell is filled with the reaction gas, the matrix effect is stronger. According to the results, even low uranium concentration in the test solution $(100 \mathrm{mg} / \mathrm{L})$ leads to a noticeable suppression of the silicon analytical signal which in turn leads to increase in the detection limit. In this case, significant matrix effect is, possibly, associated with the reduction of the silicon ion transfer efficiency due to the interaction with the gas molecules, secondly, with the increase in the number of ions of the matrix elements due to the formation of the reaction products between uranium and $\mathrm{NH}_{3}$.

Due to strong matrix influence of uranium which is an easily ionizable element (6.19 eV [11]), the only way of obtaining reliable data by direct ICP MS analysis of hydrolyzed uranium hexafluoride is the use of reference samples (certified mixtures) which have maximally similar matrix composition with the test
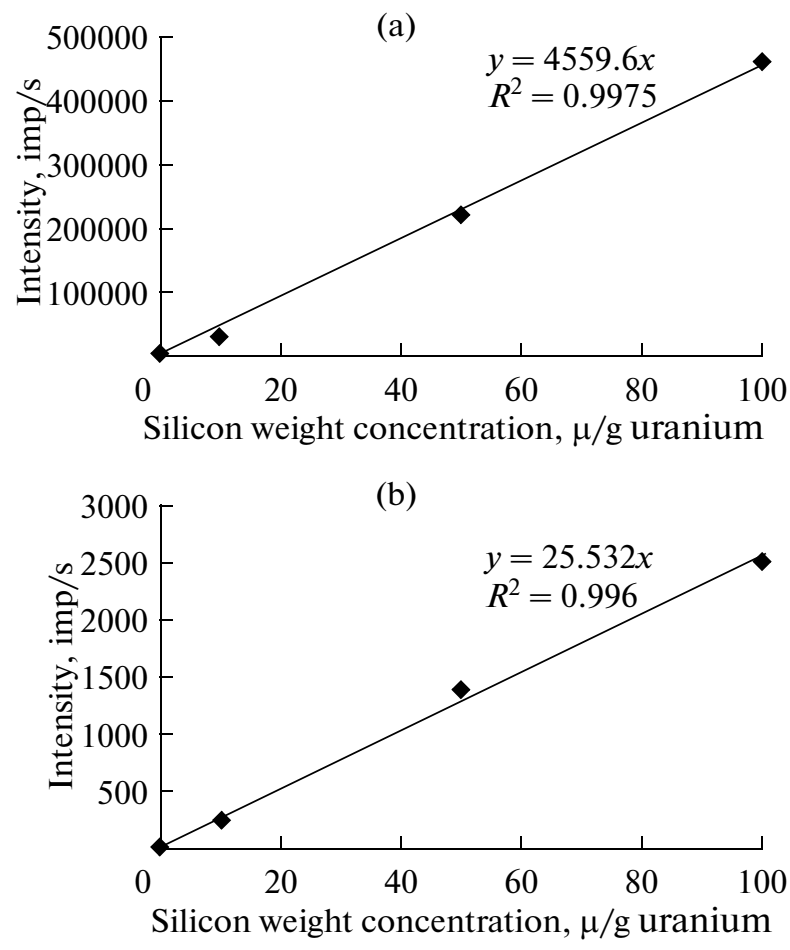

Fig. 8. Calibration curve: (a) Element-2, (b) Elan DRC II mass spectrometer.

samples. The parameters of the calibration curves are given in Fig. 8. It should be noted that the use of internal standard for the comparison of the intensity of the element analytical signal eliminates the influence of solution matrices on the efficiency of their nebulization and supplying into the plasma but it does not provide the correction of the suppressing influence of uranium due to the suppression of silicon ionization which has less atomic weight than uranium and higher ionization potential.

Study of the analytical and metrological parameters of the analysis procedures. The detection limits were estimated by the analysis of ten blank samples using $3 \sigma$-criterion. In order to prepare the blank samples, high-purity uranyl fluoride solution was diluted with deionized water to uranium concentration of $1 \mathrm{~g} / \mathrm{L}$. The experimentally achieved detection limits were 1 and $2 \mu \mathrm{g} / \mathrm{g}$ uranium for the medium resolution mode of the Element-2 spectrometer and dynamic reaction cell mode of Elan DRC II spectrometer, respectively. It should be noted the experimentally achieved detection limits can be improved if the risk of the tested sample contamination with silicon from the environment is minimized, for example, by working in clean rooms satisfying at least class 5 of the requirements to air cleanness by particle (below $0.5 \mu \mathrm{m}$ ) concentration specified in Russian State Standard ISO 14644-1-2002.

In order to examine the accuracy of the developed procedures, we have analyzed the certified mixtures 
Table 4. Results of analysis of certified mixtures and standard samples of triuranium octaoxide

\begin{tabular}{l|c|c}
\hline Sample & $\begin{array}{c}\text { Measured value, } \\
\mu \mathrm{g} / \mathrm{g} \text { uranium }\end{array}$ & $\begin{array}{c}\text { Certified value, } \\
\mu \mathrm{g} / \mathrm{g} \text { uranium }\end{array}$ \\
\hline AS-1 & $5.08 \pm 0.16$ & $5.00 \pm 0.20$ \\
AS-2 & $9.7 \pm 0.8$ & $10.0 \pm 0.4$ \\
SOU FD-5 & $11.0 \pm 1.6$ & $10.5 \pm 0.6$ \\
SOU FD-6 & $3.02 \pm 0.45$ & $3.5 \pm 0.3$ \\
SOU Ch-2 & $4.9 \pm 0.8$ & $5.2 \pm 1.0$ \\
\hline
\end{tabular}

prepared on the base of high-purity uranyl fluoride solution and standard samples of triuranium octaoxide State Reference Sample 7678, State Reference Sample 7679-99 (SOU FD-5, SOU FD-6, and SOU Ch-2); their certified parameters are given in Table 4. The results of the determination of silicon concentration in the standard samples of triuranim octaoxide and certified mixtures (Table 4) are in fine accordance with the certified values. This confirms that ICP MS can be used both for the determination of silicon in the solutions obtained after hydrolysis of uranium material and for analysis of the other uranium materials. The random error of the developed procedures characterized by relative standard deviation does not exceed $15 \%$ for the range of the determined silicon weight concentrations from 1 to $5 \mu \mathrm{g} / \mathrm{g}$.

\section{CONCLUSIONS}

The study described enabled the development of efficient procedures for the direct determination of silicon weight fraction in uranium materials by ICP MS. A practical opportunity has been demonstrated for eliminating the effect of polyatomic interference in the measurements of silicon concentration at $28 \mathrm{Da}$ using the medium-resolution mode $(m / \Delta m=4000)$ of the Element-2 mass spectrometer and the dynamic reaction cell mode of the Elan DRC mass spectrometer. The influence of the quality of the purification of water used for test sample dilution and uranyl fluoride solution on the intensity of the background signal has been studied. The optimal parameters of mass spectrometer operation in the mode of high resolution and using dynamic cell filled which ammonia have been determined. The influence of uranium matrix on the analytical signal of silicon has been investigated in various operation modes of different mass spectrometers. The transition from the standard mode (without gas supply) to the dynamic reaction cell mode of the Elan DRC II mass spectrometer leads to the enhancement of the matrix effect. In all cases the quantitative analy- sis is possible only if uranium concentration is leveled in the test and calibration solutions. The value of experimentally achieved detection limit does not depend on the mass spectrometer and is about $1-2 \mu \mathrm{g} / \mathrm{g}$ uranium. The accuracy of the results is confirmed by the analysis of certified mixtures and standard samples of triuranium octaoxide.

The developed procedures have minimal labor input and high sensitivity and are proposed for introduction into the system of analytical quality control of uranium materials.

\section{REFERENCES}

1. Pupyshev, A.A. and Epova, E.N., Analitika i kontrol', 2001, vol. 5, no. 4, p. 335.

2. Tsoupras, G. and Planitz, P., ICP Inform. Newslett., 1999 , vol. 25 , no. 7 , p. 538.

3. Smith, F.G., Wiederin, D.R., and Houk, R.S., Anal. Chem., 1991, vol. 63, no. 14, p. 1458.

4. Leloupa, C., Marty, P., Dall'avaa, D., and Perdereaub, M., Anal. Atom. Spectrom., 1997, vol. 12, no. 9, p. 945.

5. Resano, M., Verstraete, A.M., Vanhaecke, B.F., and Moens, L., Anal. Atom. Spectrom., 2002, vol. 17, no. 8, p. 897.

6. Wildner, H., Anal. Atom. Spectrom., 1998, vol. 13, no. 6, p. 573.

7. Riondato, J.F., Vanhaecke, L., and Dams, R., Anal. Atom. Spectrom., 1997, vol. 12, no. 9, p. 933.

8. Klemens, P. and Heumann, K.G., Fresenius J. Anal. Chem., 2001, vol. 371, no. 6, p. 758.

9. Ben-Younes, M., Conrad Gregoire, D., and Chakrabarti, C.L., Spectrochim. Acta, 2003, vol. 58, no. 2, p. 361.

10. Liu Hui-tao and Jiang Shiuh-Jen, Spectrochim. Acta, 2003, vol. 58, no. 1, p. 153.

11. Pupyshev, A.A. and Surikov, V.T., Mass-spektrometriya s induktivno-svyazannoi plazmoi. Obrazovanie ionov (Mass Spectrometry with Inductively Coupled Plasma), Yekaterinburg: Inst. Tverdogo Tela, 2006.

12. Tanner, S.D., Baranov, V.I., and Bandura, D.R., Spectrochim. Acta, 2002, vol. 57, no. 9, p. 1361.

13. Tanner, S.D., Baranov, V.I., and Vollkopf, U., Anal. Atom. Spectrom., 2000, vol. 15, no. 9, p. 1261.

14. Olesik, J.W. and Jones, D.R., Anal. Atom. Spectrom., 2006, vol. 21, no. 2, p. 141.

15. Chase, M.W., Davies, C.A., Downey, J.R., Frurip, D.J., McDonald, R.A., and Suverud, A.N., J. Phys. Chem. Ref. Data, 1985, vol. 14, Suppl. 1.

16. Anicich, V.G., An Index of the Literature for Bimolecular Gas Phase Cation-Molecule Reaction Kinetics. National Aeronautics and Space Administration, Pasadena: Jet Propulsion Laboratory, California Institute of Technology, 2003.

Translated by L. Malinina 